\title{
Research on age-related factors in foreign language learning
}

\section{Qin LI}

College of Foreign Languages, China Three Gorges University, China

\section{Email address:}

jennylh@sina.com

\section{To cite this article:}

Qin LI. Research on Age-Related Factors in Foreign Language Learning. International Journal of Language and Linguistics. Vol. 2, No. 1, 2014, pp. 31-37. doi: 10.11648/j.ijl1.20140201.14

\begin{abstract}
It is known that age plays a vital role in foreign language teaching and learning, thus lots of experiments have been conducted to examine the existence of critical period or to define the exact critical period for foreign language learning. This article aims to find corresponding regularity through making statistical analysis on experiments of age-related factors in foreign language learning.
\end{abstract}

Keywords: Age-Focused Research, Age-Related Factors, CP, Foreign Language Learning, Foreign Language Teaching

\section{Introduction}

There has been substantial interest around the question of what kind of role age plays in the second language (L2) learning. It is indeed an extremely intriguing question for L2 educators who must develop appropriate instructional strategies for learners of different ages as well as for L2 learners in order to achieve better language proficiency. Most of the early writing on age factor and L2 learning was based on assumption and informal observation (Bialystok \& Hakuta, 1999; Singleton, 2001).

However, from the late 1960s onwards, a large number of empirical contributions have been made for this issue. In language acquisition theory, the concept of a time frame for optimal acquisition of a language is known as the critical period hypothesis $(\mathrm{CPH})$, the idea of which was first introduced by Penfield and Roberts (1959:236), who argued that 'language acquisition is most efficient before age nine... when the human brain becomes ...stiff and rigid'. Moreover, the $\mathrm{CPH}$ was then postulated by Lenneberg (1967) who hypothesized that a decline in ability to acquire a natural language at puberty resulted from the end of neural plasticity and thus the completion of hemispheric lateralization in the human brain (and language learning after the close of the critical period would result in incomplete acquisition). Hence, lots of research has been conducted to examine the questions like whether there is also a critical period (CP) for L2 learning; if so, what the onset and offset are of this CP; if not, then whether age has crucial affect on L2 learning or what role age plays in L2 leaning.

This article will address these questions by looking at some early work on the age factor and the notion of the $\mathrm{CPH}$ with relevant evidence in respect of $\mathrm{L} 1$ acquisition. Simultaneously, the evaluation of the $\mathrm{CPH}$ in L2 learning with empirical evidence will be presented. Hence, three main sections will be discussed about here: age-focused research in L2 learning, age-related factors in L2 learning, and the implications for L2 learning and instruction. One more thing should bear in mind before start is that in this article I assume no difference between L2 learning and acquisition.

\section{Age-focused Research in L2 Learning}

How children acquire native language (L1) and the relevance of this to L2 learning has long been a highly debatable issue. There is a common notion that children can learn L2 easily and rapidly with little effort whereas adults can rarely achieve as much as children do. Actually this assumption stems from the $\mathrm{CPH}$ in respect of L1 acquisition, but now considerable attention has been paid to L2 learning. It was claimed in the $\mathrm{CPH}$ that: 'automatic acquisition from mere exposure to a given language seems to disappear [after puberty], and foreign languages have to be taught and learned through a conscious and labored effort. Foreign accents cannot be overcome easily after puberty. However, a person can learn to communicate at the 
age of forty. This does not trouble our basic hypothesis.' (Lenneberg, 1967:176)

A large number of empirical studies appear to confirm this pattern by illustrating different performance between children and adult using various tasks and measures in language acquisition. Nevertheless, a number of exceptions do exist to this pattern. Late learners, though not the majority, are sometimes able to achieve native-like proficiency in foreign language learning (Ioup et al., 1994 as cited in Singleton, 2001:83). Furthermore, according to Birdsong (1999), some late learners could perform as well as early learners even though the average performance of them was worse. Here I would like to discuss arguments about the $\mathrm{CPH}$ with empirical evidence and those against the $\mathrm{CPH}$ with counterevidence respectively.

\subsection{Research of the CPH in Language Learning}

\subsubsection{Multiple Definitions of the $\mathrm{CPH}$}

Before the discussion of research which is based on the $\mathrm{CPH}$, above all some important terminologies need to be stated clearly here. First, the $\mathrm{CPH}$ has more than one version (Birdsong, 1999). Here I would mainly discuss the CPH based on two of the possible versions, namely the maturational state hypothesis and the exercise hypothesis. The maturational state hypothesis which is the most common version of the $\mathrm{CPH}$, claims that 'maturation has an effect on the acquisition of any language; that is, if native-like levels are to be achieved, the acquisition of a first or second (a third, etc.) language must begin early in life, since the human capacity for learning languages declines with maturation.' (Hyltenstam \& Abrahamsson, 2003:557)

Birdsong (1999:5) refers to this version as the 'use it then lose it' view of the $\mathrm{CPH}$, which may imply that anyone who is first exposed to L2 after a critical period will fail to achieve native-like proficiency. However, the exercise hypothesis oppositely argues that if the language learning capacity is not exercised in early childhood, through the learning of L1, it will disappear with maturation. If this capacity is exercised during this time, however, it will remain intact.' (Hyltenstam \& Abrahamsson, 2003:557)

Similarly, Birdsong (1999:6) refers to this as 'use it or lose it' approach to the $\mathrm{CPH}$, which could indicate that late L1 learners will inevitably fail to achieve native-like proficiency, whereas late L2 learners may not necessarily fail, on the contrary, may reach native-like levels of the L2, since if the language mechanism has been exercised, it may remain available. Second, Lamendella (1977) argued that Lenneberg's definition of the critical period was overstated and put forward the term the sensitive period to emphasize that the sensitivity does not disappear at a fixed point and it is thought to fade away over a longer period of time. The difference from the $\mathrm{CPH}$ is that it dose not deny the possibility of language achievement efficiency at later ages. Nowadays, due to the extreme difficulty of drawing a clear distinction from these two terms, researchers use them interchangeably, as I do throughout this article.

\subsubsection{Empirical Evidence for the $\mathrm{CPH}$ in Language Learning}

\subsubsection{The Concept of the CPH in Biological Sciences}

The concept of the CP (Critical Period) is 'a cross-disciplinary one that has been applied to various aspects of behavioral development in both animals and humans' (Bornstein, 1987; Colombo, 1982; Immelmann \& Suomi, 1981; Oyama, 1979 as cited in Harley \& Wang, 1997). The very early theories about the CPH seem to be based on biological theories, which could be typically represented by the brain plasticity theory and an imprinting theory (Asher \& Garcia, 1982).

First, the brain plasticity theory suggests that the young child's brain has a cellular receptivity to language acquisition, which may be a function of cellular plasticity or elasticity that is controlled by a kind of biological clock (Asher \& Garcia, 1982). For instance, Penfield and Roberts (1959) have observed in accident cases that if the left hemisphere of the brain is damaged and speech is lost, children rather than adults will tend to recover in the power of speech. In addition, it could indicate that the speech function somehow may shift from the left to the right hemisphere of the brain. Furthermore, this was shown by injecting sodium amytal into the child's carotid artery to produce hemiplegia for the right hemisphere of the brain. Then with aphasia tests, it was observed that speech disappeared temporarily as long as the right hemisphere was paralyzed with the drug (Asher \& Garcia, 1982). This clinical evidence may suggest a greater cellular plasticity for children. In the light of this, Lenneberg (1967) points out the age of lateralization of speech function in the brain, which may suggest a CP of lateralization of the brain. Second, the imprinting theory has been demonstrated with birds, fish, insects, and mammals, which suggests a CP within that the organism has to be exposed to some external stimuli for the brain to develop normally (Bialystok \& Hakuta, 1994). For example, the classic study with ducklings showed that there is a CP of short duration in which the infant bird learns to follow its mother. If during this certain period the mother is absent and other objects or persons are present, then the infant bird may imprint to follow the object in preference to its mother. Therefore, it may be ratiocinated that the capacity to learn a language could be extremely operative during a $\mathrm{CP}$ in the early development of humans.

\subsubsection{Cases of Feral and Deaf Children}

Cases of feral and deaf children provide evidence for a biologically determined CP for L1. A classical example is 'Genie' (Curtiss, 1977) who was isolated and deprived of social interaction (or any linguistic input) from one and a half years old until discovered aged thirteen (post-pubescent). Her language capability then stopped at a level similar to that of 2-year-olds. Congenitally, 'Chelsea' (Curtiss, 1989 as cited in Hyltenstam \& Abrahamsson, 2003: 543) was born with a hearing deficit and reached the near-normal hearing levels at the age of thirty-one (post-pubescent) with the help of hearing aids. Finally, she 
failed to develop 'even the rudimentary aspects of grammatical structure' which was the characteristic of Genie's speech (Gleitman \& Newport, 1995 as cited in Hyltenstam \& Abrahamsson, 2003: 543). However, 'Isabelle' (Davis, 1947 as cited in Hyltenstam \& Abrahamsson, 2003: 543) had been hidden away in an attic until she was discovered at the age of six and fortunately after only one year of exposure to her L1, she reached native-like fluency. Therefore, such cases, though rare, appear to demonstrate a CP for potential to achieve native-like proficiency [between the age of seven (Isabelle) and puberty (Genie)] in L1.

\subsubsection{Evidence for the CPH in L2 Learning}

As has been stated above, according to the abundant evidence of the CPH in L1 acquisition, it is not surprising that the notion of a $\mathrm{CP}$ for L2 learning becomes widely popularized. Much research has been conducted to examine this assumption. Here, I will list several typical studies to illustrate that.

Firstly, Johnson \& Newport's (1989) study appears to be widely cited as one of the best evidence for the CP in L2 learning. The participants in this study were 46 Korean and Chinese learners of English, all of whom had lived in the United States for five years or more but varied in terms of their age of arrival (AoA) there. They were asked to provide grammatical judgments of 276 English sentences, roughly half of which were grammatical and half not. The stimuli were presented on an audiotape and they were required to provide binary judgment by circling yes or no on an answer sheet. In the end, age function becomes the most revealing finding (Birdsong, 1999), which is that the distribution of the participants' scores on the instrument plotted against their AoA in the United States (Johnson \& Newport, 1989). This finding is consistent with the $\mathrm{CPH}$, which may suggest that neurocognitive developmental factors are at work early on and suspend when maturation is complete. Some research has been carried out by a number of researchers also may be interpreted as evidence for a biological-based CP in L2 learning (see Long, 1990; Pulvermuller \& Schumann, 1994 as cited in Marinova-Todd et al., 2000: 18).

Secondly, Kim et al.'s (1997) study tends to look at the spatial representation of L1 and L2 learned at different ages in human's brain by using functional magnetic resonance imaging (fMRI), a procedure for scanning brain activity during specific tasks. The subjects were divided into two groups: one group of early bilinguals who had had their first exposure to the L2 during infancy and the other group of late bilinguals who had been exposed to the L2 at the mean age of 11.2. A sentence-generation task was given to them respectively, in which the subjects performed silently while the brain activity was recorded. The results showed that the brains of early bilinguals had a single area of activation for L1 and L2 whereas those of late bilinguals had two different areas (though adjacent) of activation for the two languages. This could indicate the age effects on brain organization. Actually, early in 1994, Wuillemin \& Richardson had carried out a relevant study and pointed out that left-hemisphere advantages were found for processing words in languages learned before age nine whereas right-hemisphere advantages were found for languages learned after puberty and language proficiency declined with age (Wuillemin \& Richardson, 1994 as cited in Marinova-Todd et al., 2000: 15). It seems that the localization of the brain is related to language proficiency.

Thirdly, Webber-Fox \& Neville (2001) conducted another research that underscored the specific areas of linguistic competence by measuring event related potentials (ERPs), which is an electrical activity in the brain in response to some event. In this study, ERPs were recorded from 10 monolingual English speakers and 53 Chinese-English bilinguals who were divided into five groups in terms of their age of immersion in English (namely, 1-3, 4-6, 7-10, 11-13, and >15). Differences between early and late bilinguals were found: there were differences in processing closed-class words at the age of onset seven though no differences appeared in normal processing of open class words; furthermore, differences in processing semantic anomalies were discovered at the age of onset eleven. These finding could suggest that language subprocesses are differentially sensitive to the timing of L2 experience, which appears to be consistent with the CPH.

Lastly, as has been discussed in Section 2.1.1, there is not only one version of the CPH. Likewise, the assumption that there could be multiple critical periods in terms of different areas of linguistic competence appears to be popularized by a number of researchers (e.g. Bialystok \& Hakuta, 1994; Long, 1990; Werker \& Tees, 1984, etc.). For instance, Werker \& Tees (1984) claimed that infants limit the phoneme distinctions they hear to those that are present in their environmental languages by around ten to twelve months of age. It appears to be a CP for phonetic perception over the age of one. However, Long (1990) argued that the offset of the CP for phonology is by the age of six while that for syntax is by the age of fifteen. Bialystok \& Hakuta (1994) suggested that the L2 phonological acquisition is subjective to a CP until early in the second decade of life. However, Singleton (2001) argued that performance on vocabulary acquisition tasks showed no major difference relating to age. Although the arguments about the specific $\mathrm{CP}$ of learning different areas of language are various, the commonality is that there appear to be multiple critical periods in L2 learning.

\subsubsection{Short Summary}

As has been discussed above, generally speaking, the $\mathrm{CPH}$ claims that native-like ultimate proficiency can be attained through mere exposure to a given language and younger learners can outperform older learners with respect to ultimate attainment regardless of some older learners who do perform better initially in some aspects of L2. Krashen et al. (1979) resolved this problem by dividing empirical studies into two types: initial rate and eventual attainment 
and concluded that

(1) adults proceed through early stages of morphological and syntactic development faster than children (where time and exposure are held constant; (2) older children acquire faster than younger children (again in early stages of morphology and syntax, where time and exposure are held constant; and (3) child starters outperform adult starters in the long run. (Krashen et al, 1979: 573)

Furthermore, the $\mathrm{CPH}$ suggests that the younger leaner is better at language learning than the older ones, which is the famous argument based on the $\mathrm{CPH}$ as the version of younger-is-better (Hyltenstam \& Abrahamsson, 2003). Simultaneously, these have always been hotly-debated issues in research areas, which I will continue to discuss in Section 2.2.

\subsection{Problems with the $\mathrm{CPH}$}

The $\mathrm{CPH}$ for L2 learning (especially the maturational state hypothesis, which is the strong version of the $\mathrm{CPH}$ ) has received a lot of criticism over years (e.g. see Birdsong \& Molis, 2001; DeKeyser, 2000; Marinova-Todd et al., 2000 , etc.). It has been argued that the credibility of the CP for L1 learning is not necessarily applicable in L2 learning because of the debatable difference process of learning L1 and L2. However, it is safe to use a strict Popperian criterion to falsify the $\mathrm{CPH}$ as 'one exception suffices to reject the hypothesis' (Long, 1990 as cited in Birdsong, 1999: 15). Here I will analyze it in detail by discussing a number of studies.

\subsubsection{The Existence of Successful Late Bilinguals}

Since it is claimed that no adult can achieve L2 competence comparable to that achieved by early bilinguals (Lenneberg, 1967) according to the $\mathrm{CPH}$, then it could be falsified if there are late bilinguals with native-like proficiency who start acquiring L2 outside a certain CP (Hyltenstam \& Abrahamsson, 2003). For instance, Van Wuijtsminkel tested Dutch learners of English after age of twelve using the task of grammaticality judgment of a subset of the Johnson \& Newport (1989) items (Van Wuijtsminkel, 1994 as cited in Birdsong, 1999: 13). Finally eight of twenty-six participants were found with native-like performance in one group and seven of eight in another group. Similarly, DeKeyser (2000) carried out a replication of Johnson \& Newport's (1989) study with the result that a few adults scored within the range of early beginners and a high level of verbal analytical ability was shown which was not a factor in the performance of early beginners.

To sum up, the most common error of the CPH in L2 learning appears to be an enormous emphasis on unsuccessful adult L2 learners and the ignorance of the older learners who achieve native-like proficiency with starting learning L2 after a certain CP (Marinova-Todd et al., 2000).

\subsubsection{No Sharp Cut-off Points}

As has been stated in Section 2.1.2, it is commonly claimed that there are onset or offset or both in terms of language proficiency during L2 learning according to the $\mathrm{CPH}$ regardless of the difference arguments about the specific cut-off points. However, there is some counterevidence to it. For example, Bialystok \& Hakuta (1994) reanalyzed Johnson \& Newport's (1989) data and found that there was a general decline in terms of language proficiency throughout the lifespan. Likewise, Birdsong \& Molis (2001) conducted a replication of Johnson \& Newport's (1989) study with Spanish learners of English, which also showed a steady linear decline of reported English proficiency as AoA increased, but no indication of a dramatically sharper rate of decline at any point (Singleton, 2001).

\subsubsection{Early Bilinguals are not Identical to Monolinguals}

Different from the acquisition of $\mathrm{L} 1$, in terms of $\mathrm{L} 2$ learning, even the early bilinguals do not tend to be identical to monolinguals and differ from monolinguals in subtle detail. Several studies indicate enduring non-native features in the ultimate achievement even of some very young starters (Bialystok \& Miller, 1999; Butler, 2000; DeKeyser, 2000; Ekberg, 1998; Fledge, 1999; Hene, 1993; Hyltenstam, 1992; McDonald, 2000 as cited in Hyltenstam \& Abrahamsson, 2003: 545).

\subsection{Summary}

As have been discussed in Section 2.1 and 2.2 respectively, the $\mathrm{CPH}$ has been indeed a useful but debatable hypothesis in terms of age role in language acquisition especially in L2 learning. Although older learners are indeed less likely to master an L2 than young children, a number of studies (as in Section 2.2) relating to age in L2 learning do reveal that 'age differences reflect differences in the situation of learning rather than in capacity to learn' (Marinova-Todd et al., 2000: 9). Furthermore, it seems that there is no critical period in L2 learning and sensible periods might be more appropriate to describe the situation that the organism is especially receptive to learning during sensitive periods, but beyond which successful learning is still possible. Therefore, it is not easy to assert absolutely that age itself is a major factor determining success in L2 learning and it may be more appropriate to conclude from these data that 'the success of L2 acquisition is constrained not by a critical period, but rather by age effects' (Bowden et al., 2005:109).

\section{Age-related Factors in L2 Learning}

After the discussion of a number of studies for or against the $\mathrm{CPH}$, still too little is known about the L2 learning in general for us to claim definitely that what finally makes learning easy at one age or difficult at another (Twyford, 1987). However, the conspiracy of several lines of psycholinguistic and sociolinguistic theory and research demonstrate possible explanations for age-related factors on L2 learning, which may provide useful implications for 
L2 educators (Ehrman \& Oxford, 1995; Gardner, Tremblay, \& Masgoret, 1997; MacIntyre \& Charos, 1996 as cited in Marinova-Todd et al., 2000:21-22) Next, I will illustrate them in detail with empirical evidence.

\subsection{General Cognitive Development}

\subsubsection{Cognitive Maturity}

Piaget (1959) has indicated the way of understanding the stages of language development as part of more complex cognitive development by showing how human cognitive development is achieved through different maturational stages with the thought processes and patterns changing systematically as people age. For example, when he observed five-to-six-years-old children playing together, he noticed that their communication often resembled monologues (they talked without much noticing of the listeners). They seem unable to engage in sustained socialized speech until they move out of what Piaget (1959) called the preoperational stage and into the concrete operational stage of cognitive development, which normally occurs around age six to seven. It seems able to explain the second point of the conclusion drawn by Krashen et al. (1979) (as stated in Section 2.1.3). In addition, Twyford (1987) argues that older learners may be able to learn at least some aspects of L2 more efficiently than younger learners because of their greater cognitive maturity, which may help them deal with the abstract nature of language better than younger learners. However, it is suggested that children may be better able to acquire an acceptable accent in a new language as a result of their certain cognitive advantages---'their intellectual capacities are less differentiated along particular lines, and they are more venturesome and less rigid in undertaking new learning tasks.' (Ausubel, 1964: 421 as cited in Harley, 1986: 15)

Furthermore, Bialystok \& Hakuta (1999) point out that the deterioration over lifespan as capacity to perform tasks under time pressure, risk-taking, stabling long-term memory codes, ability to recall details, and so on may affect the adults' language performance in various studies. In spite of different arguments about the exact effect of cognitive development in L2 learning, it does indicate that it has positive influence on L2 learning at certain stage.

\subsubsection{Literacy}

A further proposal is that the presence or absence of literal skills in L2 may have relevant effect on L2 proficiency, the process of which might be considered to be controlled by cognitive but not simply linguistic mechanisms (Bialystok \& Hakuta, 1999; Singleton, 2001). It could be believed that certain forms of instruction are more possible with literate than with illiterate. In general, younger immigrants (usually a common population for the $\mathrm{CPH}$ studies) are more likely to receive formal instruction in host language in school whereas some older immigrants (especially those without high level of literacy) may not have access to the standard written forms (Bialystok \& Hakuta, 1999). This may account for the commonly better ultimate attainment most younger immigrants achieve compared with that attained by older immigrants.

\subsection{The Environmental Factor}

\subsubsection{The environment of $L 2$}

It has been argued that living in an environment where L2 is the standard and commonly-used language has positive influence on L2 learners, especially older L2 learners' global pronunciation (Singleton, 2001). It has been demonstrated by Riney \& Flege's study with observing a group of Japanese university students who were tested at the beginning of their first year in college and then were retested forty-two months later (Riney \& Flege, 1998 as cited in Marinova-Todd et al., 2000: 25). It was found that the group who spent most of the forty-two months in English-speaking countries outperformed greatly than the group remained in Japan. It seems that the environment of L2 does play a positive role in L2 learning.

\subsubsection{The transfer of $L 1$}

It is generally believed that the growing experience of L1 may have positive or negative effect on L2 learning (Harley, 1986; Krashen et al., 1979; Singleton, 2001). Ervin-Tripp (1974) argued that L1 can enhance the ability to deal with language in general and hypothesized that older learners will learn faster than younger learners in terms of phonology, syntax and semantics of L2 with the help of their learning strategies of L1 (Ervin-Tripp, 1974 as cited in Harley, 1986). On the contrary, it has been claimed that there may be negative transfer of age-related L1 production strategies to L2 by young learners (Zobl, 1983 as cited in Harley, 1986). For example, the study conducted by Yeni-Komshian et al. indicated that 'learners who live in an L2 environment do not automatically achieve native-like pronunciation in the L1; only those who depart from their L1 environment after age 8 consistently retain a native-like pronunciation of in their L1.' (Yeni-Komshian et al., 1999 as cited in Marinova-Todd et al., 2000: 25)

This could suggest that children may obtain high levels of proficiency in their L2 at the cost of their L1; similarly, older learners tend to retain native-like proficiency in their L1 at the expense of their L2. In addition, another study conducted by Jia \& Aaronson suggests the age factor on the L1 and L2 with the result that immigrants arriving before age ten seem to switch their dominant language from L1 to L2 whereas immigrants arriving at ages older than ten tend to maintain their L1 (Jia \& Aaronson, 1999 as cited in Singleton, 2001). In short, the transfer of L1 appears to be relevant to L2 learning in terms of age.

\subsection{Cross-linguistic Factors---The Input and Use of L2}

Another age-related source of variance in L2 learning to be discussed here is the impact of different amounts and patterns of L2 input and use. According to Krashen et al. (1979), natural comprehensible input can be regarded as the fundamental principle in L2 acquisition, and the ability to attain comprehensible input may increase with age. It may 
account for the success of those late starters in L2 who achieve native-like proficiency in the end. Moreover, the amount and patterns of L2 input and use may be taken into account, which appears to be an impact of age on behavioral and lifestyle choices. For instance, Flege and his colleagues have demonstrated the amount of time of exposure in a L2 environment has great influence on L2 pronunciation (Flege et al., 1997 as cited in Singleton, 2001: 83).

\subsection{Affective Factors}

The final age-related variance I will discuss here is affective factors which may include motivation, anxiety, personality, self-confidence, willingness to communicate and other characteristics that might affect learners' attitude toward L2 learning. These factors have been hypothesized to be partially responsible for the differences between children and adults in L2 learning (Ellis, 2004; Twyford, 1987). For example, the anxiety barrier might explain why older learners (including some adolescents) are less successful at school language learning than younger learners. A number of studies have shown anxiety is negatively related to L2 achievement (Bailey, 1983; Horwitz \& Cope, 1986 as cited in Ellis, 2004:539). Personality could affect L2 learning as well since it is suggested that 'extraverted learners may have an advantage when the criterion is natural communicative language' (Ellis, 2004: 541). Likewise, self-confidence may also work as a filter or barrier as well as the willingness to communicate (Singleton, 2001; Twyford, 1987). Here, I will put more emphasis on the discussion in terms of motivation.

\subsubsection{Motivation}

Nowadays, motivation has attracted more attention from researchers and educators than any other individual affective factor, which is 'a reflection not just of its importance for understanding language learning but also of the potential for maximizing its success' (Ellis, 2004: 536). Noels et al. (2000) puts forward two types of motivation by providing a detailed model for them, namely extrinsic motivation (which refers to the motivation to achieve instrumental end) and intrinsic motivation (which refers to the motivation to engage in a specific activity). A factor-analytic study which was conducted by Noels et al. (2000) through responding to a questionnaire by Anglophone learners of L2 French in Canada largely confirmed this classification and further suggested that intrinsic motivation contributes strongly to L2 learning. For example, older learners are more likely to feel the need of learning a language for academic success or for economic survival and thus work harder. However, although younger learners may lack such extrinsic motivation, they might succeed as they do in natural acquisition settings as a result of their intrinsic motivation to participate actively with their peers (Gardner, 1985 as cited in Ellis, 2004:536).

\section{Implications for L2 Learning and Instruction}

As has been discussed in detail in Section $2 \& 3$, a general overview of the role of age in L2 learning becomes clear. In short, children may have some advantage over adults in terms of L2 learning, but the advantage appears to be tested only in naturalistic settings (which refer to the context where there is a lot of contact with L2). However, there is little evidence to show that younger children are more successful than older children or adults when L2 is learnt in classroom (Bialystok \& Hakuta, 1999; Harley, 1986; Singleton, 2001). Furthermore, a number of age-related factors appear to have inevitable influence on L2 learning (as stated in Section 3), which cannot be ignored in the real L2 learning and instruction.

First, L2 learners, educators, and parents should not conceive the assumption that only the early L2 learning will be effective and thus try to arrange children to learn L2 as early as possible regardless of children's own willing. From the discussion in Section 2\& 3, we can see that age, not alone, but accompanied with a number of age-related factors, appears to play an important role in L2 learning, after all not a determining role. Hence, we cannot simply assume that the early the better, especially in the case of classroom instruction (Marinova-Todd et al., 2000).

Second, authentic communication experience in L2 appears to be very helpful for L2 learners based on most of age-focused studies (as stated in Section 2). Early bilinguals, most of the time, seem to be more successful than late bilinguals, largely because of their more exposure to the nurturing L2 environment, simplified L2 input, and their more opportunities to communicate with their peers in L2 (Bialystok \& Hakuta, 1994; Singleton, 2001).

Third, those age-related factors (discussed in Section 3) should be taken into account by L2 learners and educators during the process of L2 learning. By being alert to these age-related variables active in L2 learners who enter any classroom, educators could base instruction on what individual learners are ready to accomplish. Furthermore, educators can try to design activities in L2 teaching in order to raise learners' interest and develop their self-confidence with more encouragement and less criticism. Educators' attention to learners' motivation of learning L2 tends to be of great significance as well.

\section{Conclusion}

After the discussion in detail in this article about the role of age in L2 learning through evaluating the $\mathrm{CPH}$, it can suggest that not all children can achieve native-like L2 proficiency while not all adults cannot achieve as much as children do in L2 learning and acquisition. Although it seems that children have some advantage over adults in terms of neurolinguistic, social, and cognitive aspects, it appears to be tested only in naturalistic settings. From this, 
we can see that age does affect L2 learning, but not absolutely. In addition, a number of age-related factors are argued to be of great importance in terms of L2 learning. Even though L2 learners' ages cannot be changed, their learning strategies, amount and pattern of L2 input, learning environment, motivation and other factors can be changeable (Marinova-Todd et al., 2000). To conclude, it is not an absolute age factor that affects L2 learning, but a number of age-related factors at work. Thus, L2 educators should take all these elements into consideration to tailor learners' needs and aptitudes to improve their L2 learning.

This paper belongs to the project of youth fund of China Three Gorges University (No. 2013A024) "The Integrative Study of ARCS Model of Motivation and College English Teaching ", and is a part of it.

\section{References}

[1] Asher, J.J. \& Garcia, R. (1982) The optimal age to learn a foreign language. In S. D. Krashen, R.C. Scarcella, \& M.H. Long (eds) Child-Adult Differences in Second Language Acquisition (pp. 3-12). Rowley, MA: Newbury House Publishers.

[2] Bialystok, E. \& Hakuta, K. (1994) In Other Words: The Science and Psychology of Second Language Acquisition. New York: Basic Books.

[3] Bialystok, E. \& Hakuta, K. (1999) Confounded age: linguistic and cognitive factors in age differences for second language acquisition. In D. Birdsong (eds) Second Language Acquisition and the Critical Period Hypothesis (pp. 161-181). Mahwah, NJ: Lawrence Erlbaum Aassociates.

[4] Birdsong, D. (1999) Introduction. Whys and why nots of the critical period hypothesis for second language acquisition. In D. Birdsong (eds) Second Language Acquisition and the Critical Period Hypothesis (pp. 1-22). Nahwah, NJ: Lawrence Erlbaum Associates.

[5] Birdsong, D. \& Molis, M. (2001) On the evidence for maturational constraint in second language acquisition, Journal of Memory and Language, 44, 235-249.

[6] Bowden, H.W., Sanz, C., \& Stafford, C.A. (2005) Individual differences: Age, sex, working memory and prior knowledge. In C. Sanz (eds) Mind and Context in Adult Second Language Acquisition (pp. 105-140). Washington, D.C.: Georgetown University Press.

[7] Curtiss, S. (1977) Genie: A Psycholinguistic Study of a Modern Day "Wild Child". London: Academic Press.

[8] DeKeyser, R. (2000) The robustness of critical periods effects in second language acquisition, Studies in Second Language Acquisition, 22, 499-533.

[9] Ellis, R. (2004) Individual differences in second language learning. In A. Davies \& C. Elder (eds) The Handbook of Applied Linguistics (pp. 525-551). Oxford: Blackwell.

[10] Harley, B. (1986) Age in Second Language Acquisition.
Clevedon: Multilingual Matters.

[11] Harley, B. \& Wang, W. (1997) The critical period hypothesis: Where are we now? In A.M.B. de Groot \& J.F. Kroll (eds) Tutorial in Bilingualism: Psycholinguistic perspectives (pp. 19-51). London: Lawrence Erlbaum.

[12] Hyltenstam, K. \& Abrahamsson, N. (2003) Maturational constraints in SLA. In C.J. Doughty \& M.H. Long (eds) The Handbook of Second Language Acquisition (pp. 539-585). Oxford: Blackwell.

[13] Johnson, J. \& Newport, E. (1989) Critical period effects in second language learning: The influence of maturational state on the acquisition of ESL, Cognitive Psychology, 21, 60-69.

[14] Kim, K.H.S., Relkin, N.R., Kyoung-Min, L. \& Hirsch, J. (1997) Distinct cortical areas associated with native and second languages, Nature, 388, 171-174.

[15] Krashen, S.D., Long, M.H., \& Scarcella, R.C. (1979) Age, rate, and eventual attainment in second language acquisition, TESOL Quarterly, 13, 573-583.

[16] Lamendella, J. (1977) General principles of neurofunctional organization and their manifestations in primary and non-primary language acquisition, Language Learning, 27, 155-196.

[17] Lenneberg, E. (1967) Biological Foundations of Language. New York: Wiley.

[18] Long, M. (1990) Maturational constraints on language development, Studies in Second Language Acquisition, 12, 251-285.

[19] Marinova-Todd, S.H. , Marshall, D.B. \& Snow, C.E. (2000) Three misconceptions about age and L2 learning, TESOL Quarterly, 34, 9-34.

[20] Noels, K., Pelletier, L., Clement, R., \& Vallerand, R. (2000) Why are you learning a second language? Motivational orientations and self-determination theory, Language Learning, 50, 57-85.

[21] Penfield, W., \& Roberts, L. (1959) Speech and Brain-mechanisms. Princeton, NJ: Princeton University Press.

[22] Piaget, J. (1959) The Language and Thought of a Child. London: Routledge.

[23] Singleton, D. (2001) Age and second language acquisition, Annual Review of Applied Linguistics, 21, 77-89.

[24] Twyford, C.W. (1987) Age-related factors in second language acquisition, http://www.ncela.gwu.edu/pubs/classics/focus/02bage.htm. Accessed 5 Feb. 2012.

[25] Webber-Fox, C. \& Neville, H. (2001) Sensitive periods differentiates processing of open- and close-class words: An ERP study of bilinguals, Journal of Speech, Language, and Hearing Research, 44, 1338-1353.

[26] Werker, J.F. \& Tees, R.C. (1984) Cross-language speech perception: Evidence for perceptual organization during the first year of life, Infant Behavior and Development, 7, 49-63. 